\title{
The Effect of Nylon 6.6 Nanofiber Layers on Mechanical Properties of Epoxy
}

\author{
Ahmet Yapici ${ }^{1}$, Vildan Özkan ${ }^{1}$, Murat Yıldız ${ }^{1}$, Mehmet Okan Erdal ${ }^{2}$, Lokman \\ $\mathrm{Gemi}^{2}$ and Şakir Yazman ${ }^{3}$ \\ ${ }^{1}$ Mechanical Engineering Department, Iskenderun Technical University, Iskenderun 31200, Turkey \\ ${ }^{2}$ Seydisehir Vocational School, Necmettin Erbakan University, Konya 42370, Turkey \\ ${ }^{3}$ Ilgin Vocational School, Selcuk University, Konya, 42600, Turkey
}

ABSTRACT-

In this study mechanical properties of epoxy resin reinforced with different numbers of nanofiber layers of nylon 6.6 which produced with electrospinning method was investigated. Solution of 10 wt \% of Nylon 6.6/ formic acid was used for electrospinning. The special molds were prepared to produce the laminated composite plates. Static tensile tests were performed, and the specimens were evaluated with respect to tensile strength and elongation at break, which are aspects of their basic mechanical properties.

Keywords - Electrospinning, Nanofiber, Nylon 6.6, Laminated composites

Date of Submission: 10 November 2016 Date of Accepted: 05 December 2016

\section{INTRODUCTION}

The epoxy resins have been widely used as adhesives and matrices of insulation material of superconducting magnets, due to their good electrical insulation properties, advantageous heat and chemical resistance, high elastic modulus, low density, strong bond ability, and convenient manufacturing process [1-3]. To reach the desired mechanical and thermal properties, one approach is the addition of micro- or nanofillers such as nanofibers or nano particles to a polymer [4,5]. When the diameters of polymer fiber materials are shrunk from micrometers to nanometers, there appear several amazing characteristics such as flexibility in surface functionalities, very large surface area to volume ratio, and superior mechanical performance compared with any other known form of the material [6]. The present work investigates the use of an electrospun polymeric nanofibrous layers to enhance composite laminate mechanical performances. Nylon 6.6 electrospun nanofiber layers are fabricated by electrospinning and placed in an epoxy matrix. Different layer numbers $(5,10$ and 15 layers $)$ were used to reinforce the epoxy. After the tensile test the tensile load- displacement results were evaluated.

\section{EXPERIMENTAL}

Nylon 6.6 was purchased from Sigma-Aldrich company. Nylon 6.6 granules was dissolved at $10 \mathrm{wt} \%$ in formic acid (Fig. 1). The solution was stirred at room temperature and stirred with ultrasonic bath to ensure its dissolution.

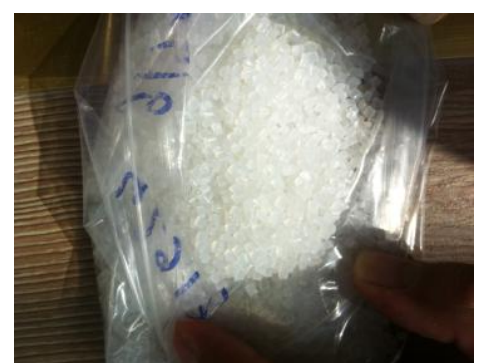

(a)

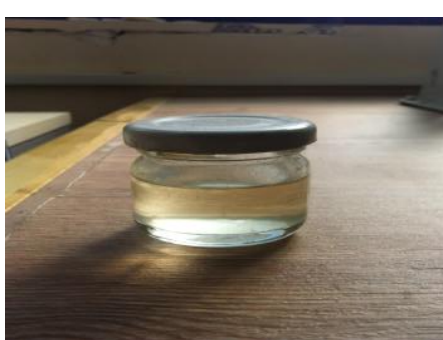

(b)

Fig. 1. Solution preparation (a) Nylon 6.6 granules, (b) Solution

Electrospinning were carried out on a horizontal setup as shown in Fig. 2. A syringe was used as injector. The electrospinning setup consisted of a syringe, a syringe pump, a grounded electrode connected with rotating drum, and a high voltage power supply which could generate positive DC voltages up to $50 \mathrm{kV}$. The value of electrospinning parameters were chosen as follows: voltage $30 \mathrm{kV}$, distance between the tip of the spinneret and 
collector $20 \mathrm{~cm}$, solution feed rate $0.3 \mathrm{~mL} / \mathrm{h}$. Electrospinning was performed at room temperature and the syringe set up was enclosed in a chamber. The discharged jet undergoes a whipping action that further elongates the polymer, and the repulsive electrostatic field splits the jet into fine submicron fibers that were collected on a grounded metal collector or drum. The polymer fiber diameter and its alignment depends on the type and concentration of polymer in the solution, applied voltage, flow rate, needle diameter, distance between needle and collector drum, and the type of collector.

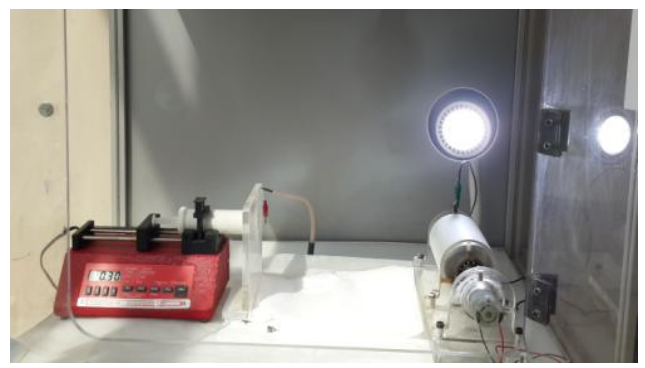

Fig. 2. Electrospinning setup

For one sheet nylon 6.6 layer $10 \mathrm{~mL}$ solution was used. Fig. 3 shows the layer at the end of spinning.

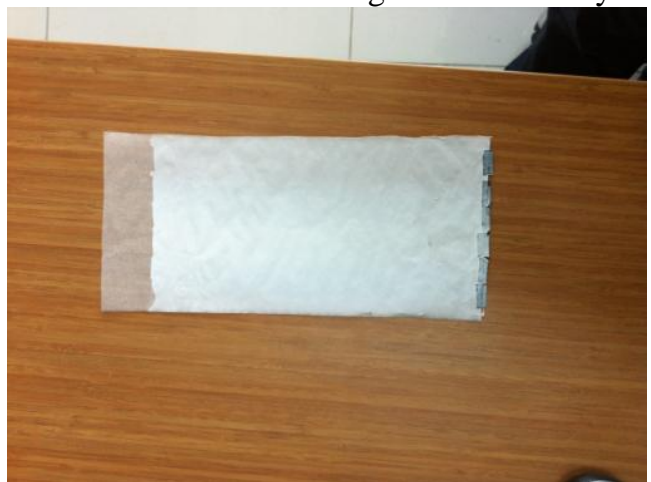

Fig. 3. Naylon 6.6 nanofiber layer

The specimens were cut in accordance with ASTM D638-10 as shown in Fig. 4.

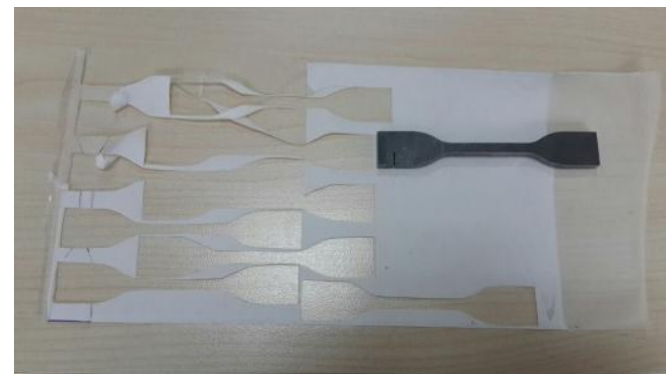

Fig. 4. Specimens cut

A special mold was designed and manufactured to produce laminated composites (Fig. 5). The MGS L160 was used as a resin and H160 as a hardener. After wetting the layers they placed in the mold and cured in room temperature.

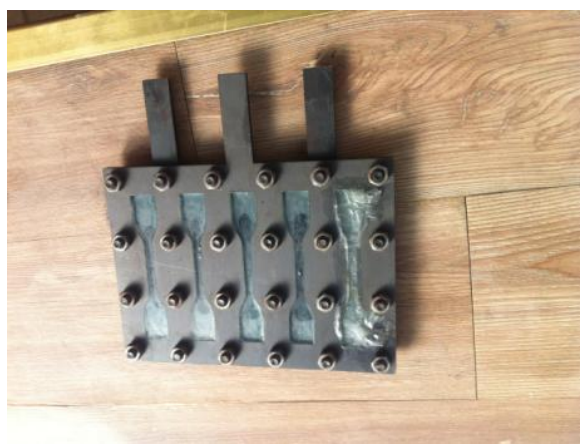

Fig. 5. Specimen preparation 
Fig. 6 shows the specimens reinforced with 5, 10 and 15 nanofiber layers of nylon 6.6 after the manufacturing process.

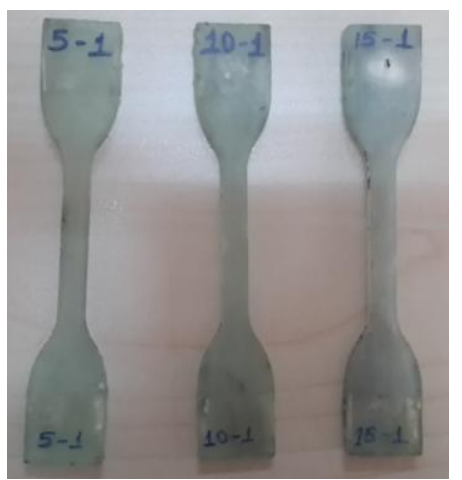

Fig. 6. Nylon 6.6 reinforced specimens

Table 1 shows weight percent of nylon 6.6 layers in epoxy composites.

Table 1. Weight percent of nylon 6.6

\begin{tabular}{|c|c|}
\hline Layer numbers & wt \% \\
\hline 5 & 0.4125 \\
\hline 10 & 1.2069 \\
\hline 15 & 3.1616 \\
\hline
\end{tabular}

III. RESULTS AND DISCUSSION

The obtained results of the tensile tests of epoxy and composites with the reinforcement content of 5, 10 and 15 layers are presented in Fig. 7. The presented values demonstrate the changes in the mechanical behavior of the epoxy under tensile loading.

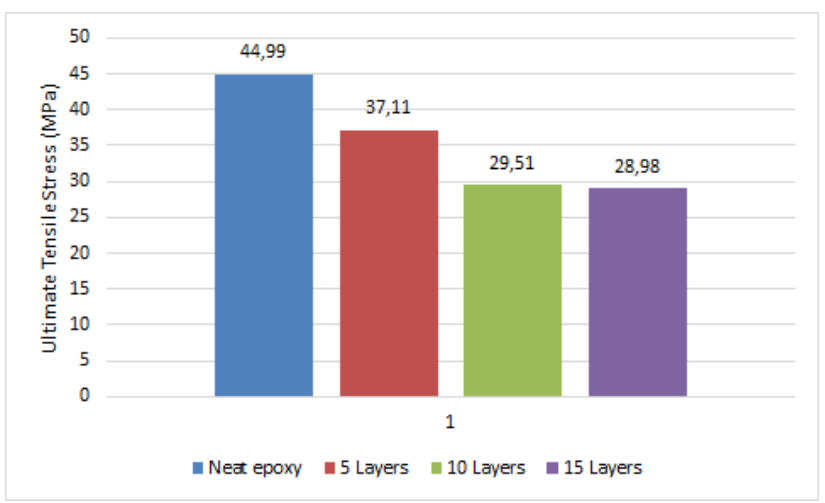

Fig. 7. Ultimate tensile stress

Fig. 8 shows the displacement values at break.

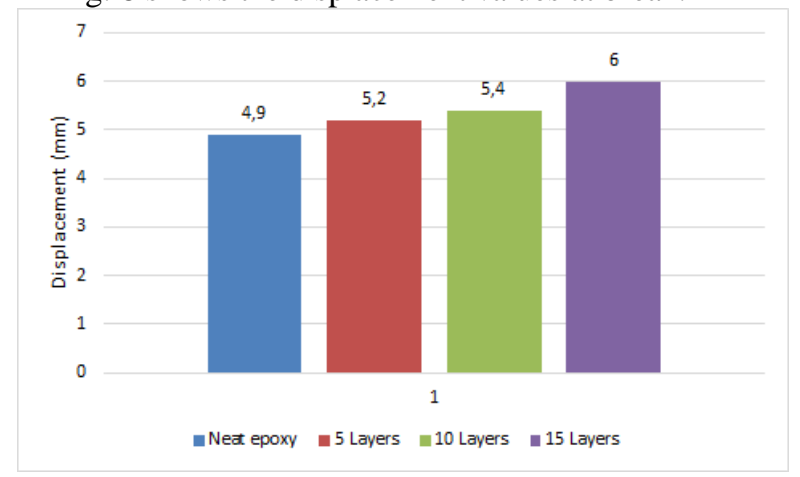

Fig. 8. Displacement at break 
It is seen that insert 5 layers in epoxy $(0.4125 \mathrm{wt} \%)$ decreases the strength $17.52 \%$ and gives $6.12 \%$ elongation compared to neat epoxy. Similarly insert 10 and 15 layers $(1.2069$ and $3.1616 \mathrm{wt} \%)$ decreases the strength $34.41 \%$ and $34.59 \%$ but increases the elongation $10.2 \%$ and $22.44 \%$ respectively.

\section{CONCLUSION}

The nanofiber nylon 6.6 layers were produced using electrospinning by dissolving nylon 6.6 granules in formic acid solution. The nylon 6.6 layers were placed in epoxy using special mold. The mechanical properties of neat epoxy, 5 layers, 10 layers and 15 layers nylon 6.6 reinforced composites plates were investigated.

As a result of tensile tests, the tensile stress values decreases and the elongation at break increases by the increasing the layer numbers.

\section{REFERENCES}

[1] Ueki T, Nishijima S, Izumi Y. Designing of epoxy resin systems for cryogenic use. Cryogenics (Guildf) 2005;45:141-8. doi:10.1016/j.cryogenics.2004.07.002.

[2] Kang S, Hong S Il, Choe CR, Park M, Rim S, Kim J. Preparation and characterization of epoxy composites filled with functionalized nanosilica particles obtained via sol-gel process. Polymer (Guildf) 2001;42:87987. doi:10.1016/S0032-3861(00)00392-X.

[3] Shan X, Huang C, Yang H, Wu Z, Li J, Huang R, et al. The Thermal Expansion and Tensile Properties of Nanofiber-ZrW2O8 Reinforced Epoxy Resin Nanocomposites. Phys Procedia 2015;67:1056-61. doi:10.1016/j.phpro.2015.06.200.

[4] Chen IH, Wang CC, Chen CY. Preparation of carbon nanotube (CNT) composites by polymer functionalized CNT under plasma treatment. Plasma Process Polym 2010;7:59-63. doi:10.1002/ppap.200900067.

[5] Li J, Wu Z, Huang C, Liu H, Huang R, Li L. Mechanical properties of cyanate ester/epoxy nanocomposites modified with plasma functionalized MWCNTs. Compos Sci Technol 2014;90:166-73. doi:10.1016/j.compscitech.2013.11.009.

[6] Huang ZM, Zhang YZ, Kotaki M, Ramakrishna S. A review on polymer nanofibers by electrospinning and their applications in nanocomposites. Compos Sci Technol 2003;63:2223-53. doi:10.1016/S02663538(03)00178-7. 